\title{
Arthroscopic posterior cruciate ligament reconstruction with allograft versus autograft
}

\author{
Xiujiang Sun ${ }^{1}$, Jianfeng Zhang ${ }^{2}$, Xiaoyi Qu ${ }^{3}$, Yanping Zheng ${ }^{1}$
}

\author{
'Department of Orthopedics, Qilu Hospital, Shandong University, Jinan, China \\ ${ }^{2}$ Department of Orthopedics, Yantaishan Hospital, Yantai, China \\ ${ }^{3}$ Nurse School of Yantai, Yantai, China
}

Submitted: 2 March 2013

Accepted: 11 May 2013

Arch Med Sci 2015; 11, 2: 395-401

DOI: 10.5114/aoms.2015.50971

Copyright $\odot 2015$ Termedia \& Banach

\section{Abstract}

Introduction: The aim of the study was to compare and analyze retrospectively the outcomes of arthroscopic posterior cruciate ligament reconstruction with autograft versus allograft.

Material and methods: Seventy-one patients who underwent arthroscopic posterior cruciate ligament reconstruction with an autograft or allograft met our inclusion criteria. There were 36 patients in the autograft group and 35 patients in the allograft group. All the patients were evaluated by physical examination and a functional ligament test. Comparative analysis was done in terms of operation time, incision length, fever time, postoperative infection rate, incidence of numbness and dysesthesia around the incision, as well as a routine blood test.

Results: The average follow-up of the autograft group was $3.2 \pm 0.2$ years and that of the allograft group was $3.3 \pm 0.6$ years; there was no significant difference $(p>0.05)$. No differences existed in knee range of motion, Lysholm scores, International Knee Documentation Committee standard evaluation form and Tegner activity score at final follow-up $(p>0.05)$, except that patients in the allograft group had a shorter operation time and incision length and a longer fever time $(p<0.05)$. We found a difference in posterior drawer test and KT-2000 arthrometer assessment $(p<0.05)$. The posterior tibia displacement averaged $3.8 \pm 1.5 \mathrm{~mm}$ in the autograft group and 4.8 $\pm 1.7 \mathrm{~mm}$ in the allograft group $(p<0.05)$. The incidence of numbness and dysesthesia around the incision in the autograft group was higher than that in the allograft group $(p<0.05)$. There was no infection postoperatively. The white blood cells and neutrophils in the allograft group increased more than those in the autograft group postoperatively $(p<0.05)$.

Conclusions: Both groups of patients had satisfactory outcomes after the operation. However, in the instrumented posterior laxity test, the autograft gave better results than the allograft. No differences in functional scores were found.

Key words: posterior cruciate ligament reconstruction, autograft, allograft, arthroscopy.

\section{Introduction}

The posterior cruciate ligament $(\mathrm{PCL})$ plays a very important role in the posterior stability and function of the knee joint. Posterior cruciate ligament injuries occur in up to $44 \%$ of all knee injuries [1], but isolated PCL injuries have a reported incidence of 3.5\% [2]. Posterior cruciate

\author{
Corresponding author: \\ Yanping Zheng MD \\ Department of Orthopedics \\ Qilu Hospital \\ Shandong University \\ No. 107 WenhuaXi Road \\ Jinan, China \\ Phone: +86 15953527868 \\ E-mail: 33439155@qq.com
}


ligament injuries often appear in sport injuries or high-energy trauma [3-6]. The treatment of the $\mathrm{PCL}$ injury is controversial, although the instrument and technique have been improved greatly. There are documents reporting the encouraging management of isolated PCL tears [7], but PCL deficiency can cause severe instability of the knee and degeneration of the knee [8]. Posterior cruciate ligament reconstruction receives wide interest in the orthopedic literature [9].

The graft choice is another question we need to consider. Artificial ligaments have shown poor clinical outcomes due to loosening, fatigue failure, and a strong host immune response [10, 11]. Many studies have reported that bone-patellar-bone and hamstring autografts can produce good clinical outcomes in ligament reconstruction [12, 13]. However, autografts may cause greater surgical trauma and postoperative donor-site morbidity. The hamstring autograft harvested can cause weakening of the flexor apparatus [14]. The use of allografts can minimize the operative trauma and eliminate the donor-site morbidity [15]. Also, it is more appropriate for revision surgery and multiple ligament injury [16]. Several studies have compared allografts with autografts in anterior cruciate ligament $(\mathrm{ACL})$ reconstruction. The results show that the allograft is a reasonable alternative to the autograft $[17,18]$. The allograft tissue has its own problems, such as disease transmission, bacterial, viral, and host immune response, delayed incorporation, and bone tunnel enlargement [19-22].

The purpose of our studies was to compare the outcomes of PCL reconstruction using autografts and allografts retrospectively. Our hypothesis was that the clinical results of $P C L$ reconstruction using allografts were equivalent to those using autografts.

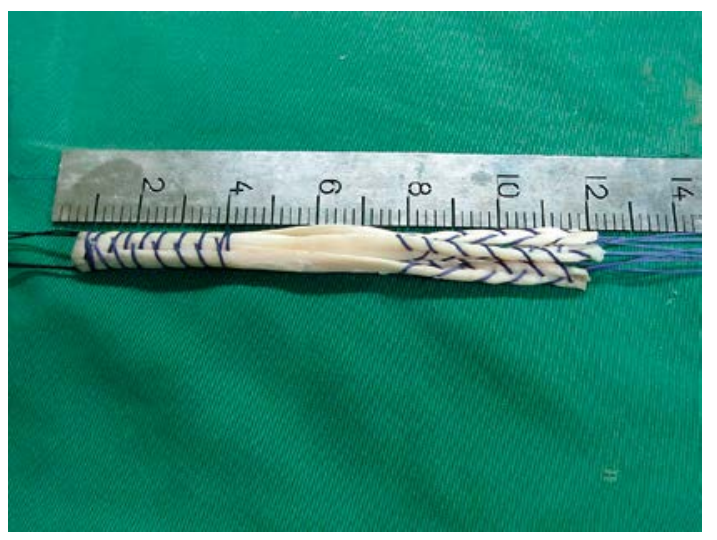

Figure 1. The single bundle four-strand graft was about $12 \mathrm{~cm}$ long. The four ends of the four-strand tendon were sutured with ' 2 ' polyester whipstitch-style sutures separately. Its diameter was 8-9 $\mathrm{mm}$

\section{Material and methods}

\section{Patients selection}

The study was a retrospective observational analysis. This study compared the outcomes of primary $P C L$ reconstructions with autografts or allografts from April 2005 to July 2009. Exclusion criteria included ACL injury combined, vascular and neural complications, collateral ligament injury (grade III and above), large cartilage lesion (Outerbridge grade III or IV larger than $1.0 \mathrm{~cm}$ in diameter) and so on. The patients with meniscus injury combined were not excluded. Seventy-one patients met our inclusion criteria. Ten patients were excluded due to $A C L$ injury combined (3), common peroneal nerve injury (1), grade III collateral ligaments injury (4), and large cartilage lesion (2).

The diagnosis was confirmed through orthopedic examination and preoperative magnetic resonance imaging (MRI). The orthopedic examination and MRI have an important role in diagnosis [23]. All the patients had a symptomatic isolated $\mathrm{PCL}$ rupture with the three-plus posterior drawer test. All the patients had significant posterior instability. All procedures were performed by the same surgeon with the same technique, but the surgeon did not take part in the rehabilitation process. Graft selection was based on patient preference. All rehabilitations were the same and were performed by the same physician.

\section{Harvest and preparation of grafts}

We harvested the autogenous hamstring (semitendinosus and gracilis) tendon from the injured side. After the tendons were folded over at their centers, the diameter should have been at least $8 \mathrm{~mm}$. Otherwise, those of the uninjured side were harvested. All allogeneic tendons were supplied by a certified tissue bank. The allogeneic tendon was sterilized with gamma irradiation at a dose of $2.5 \mathrm{mrad}$. The allogeneic tendon was dipped in physiological saline with gentamicin. Both the tendons were folded over at their centers, creating a four-strand graft (Figure 1). The folded end was fixed in a femoral tunnel. The four ends of the four-strand tendon were sutured with ' 2 ' polyester whipstitch-style sutures separately. The diameter was $8-9 \mathrm{~mm}$. The length was at least $12 \mathrm{~cm}$. All tendons were prepared in an identical fashion, and the grafts were pretensioned under $20 \mathrm{lb}$ for $20 \mathrm{~min}$.

\section{Surgical technique}

We made the standard anterolateral and anteromedial portals. Firstly, the preliminary diagnosis arthroscopy was performed, in order to find 
any meniscal lesions and other injuries. Once the meniscal lesions were found, the partial meniscectomy or repair would be performed. After that, the posteromedial portal was made so as to find the rupture of the PCL and localize the exit point of the tibia tunnel. During the operation process, if the PCL remnant is observed, it should be preserved, because it is helpful to obtain successful outcomes (Figure 2). The exit point was $1.5 \mathrm{~cm}$ below the joint surface, lateral to the midline in the posterior recess of the tibia. The tunnel size should match the graft diameter. When drilling the tunnel, one should take care not to damage the popliteal vessels.

The femoral tunnel centre was $6 \mathrm{~mm}$ to $8 \mathrm{~mm}$ from the distal articular surface with the same opening measuring as the graft diameter. It was placed at the half-past-one or half-past-ten position according to the side (Figure 3). After the graft was passed through the tibia tunnel and then into the femoral tunnel, its femoral end was fixed with absorbable interference screws (DePuy Mitek). At the knee $70^{\circ}$ flexed and tibia anterior drawer position, the tibia end was fixed with absorbable interference screws (DePuy Mitek) after moving the knee 20 times through a full range of motion.

\section{Postoperative rehabilitation}

Static quadriceps and straight leg-raising exercises were started at once after the operation. All patients were non-weight-bearing for 6 weeks. A hinged brace was necessary for the patient in the first 2 months. The knee was braced in full extension for 2 weeks. From the third week, the knee passive flexion began twice a day. A $90^{\circ}$ range of flexion was allowed after 4 weeks postoperatively. The knee flexion was limited to $0-120^{\circ}$

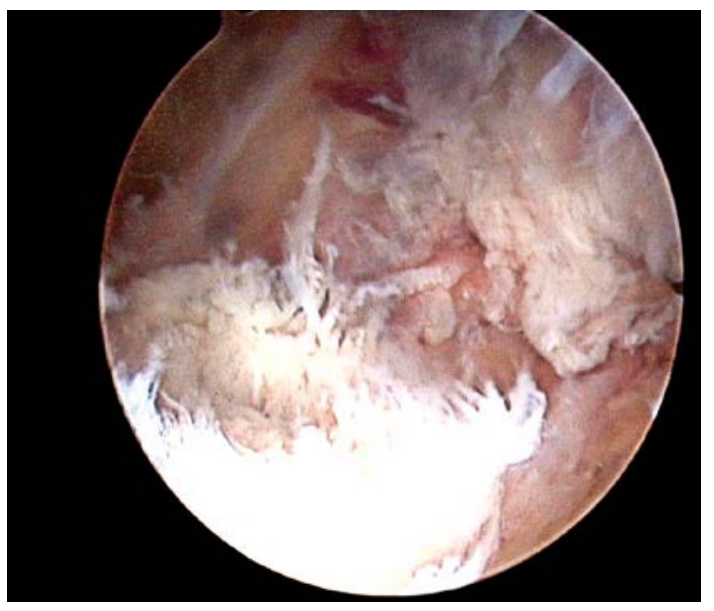

Figure 2. The torn post cruciate ligament was found through the posteromedial portal. The ligament was torn completely. The PCL remnant was observed. In the operation process, the remnant was conserved after 3 months postoperatively and $0-140^{\circ}$ after 4 months postoperatively. Six weeks postoperatively the patient could walk with full weight bearing. Four months postoperatively, a progressive running program was initiated. After 10 postoperative months, contact sports activities were allowed.

\section{Evaluation}

The postoperative assessments were performed at the follow-up point $(1,2,4,6,9$, and 12 months and then yearly) to obtain measures of the clinical outcomes. The operation time, incision length, postoperative fever time (when the axillary temperature is more than $37.2^{\circ} \mathrm{C}$ ), infection rate and routine blood test were compared after the operation. The incidence of numbness and dysesthesia around the incision were also compared. The posterior drawer test and the KT2000 test were used to evaluate the posterior stability of knee joints. The posterior laxity was assessed by manual-maximum KT-2000 tests at the knee positioned with $90^{\circ}$ flexion. Side-to-side differences in posterior laxity were determined. Functional tests included the range of motion (ROM), international Knee Documentation Committee standard evaluation form (IKDC), Lysholm scores and Tegner activity score. To minimize bias, all evaluations were performed by the same investigator, who did not take part in our study. A routine blood test was performed preoperatively and 1 day postoperatively to compare the number of white blood cells, neutrophilic granulocytes and other cells.

\section{Statistical analysis}

SPSS 13.0 was used for statistical analysis. The independent-samples and paired-samples $T$-tests

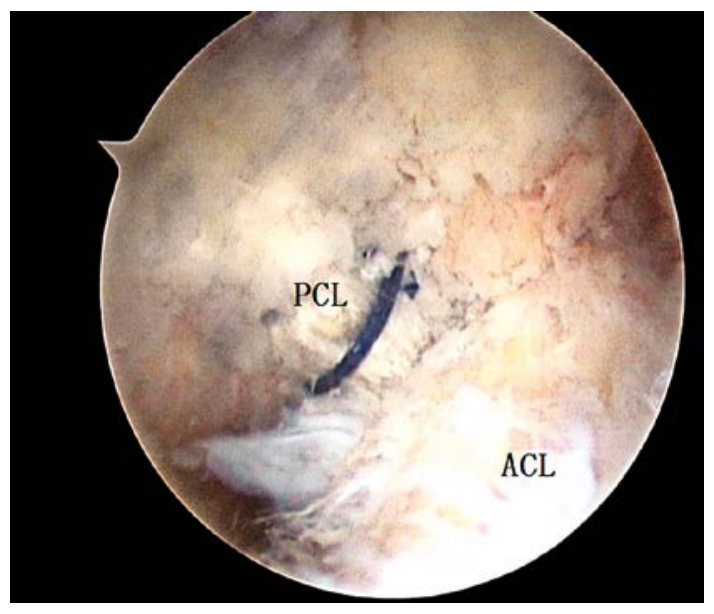

Figure 3. The transplanted grafts are seen at the time of surgery at $90^{\circ}$ of knee flexion in arthroscopic view by use of the lateral infra-patellar portal. The PCL was fixed in the femoral tunnel, posteromedial to the $\mathrm{ACL}$ 
Table I. Demographics of both groups

\begin{tabular}{|c|c|c|c|c|c|c|}
\hline \multirow[t]{2}{*}{ Group } & \multirow[t]{2}{*}{$N$} & \multicolumn{2}{|c|}{ Gender } & \multirow[t]{2}{*}{ Age } & \multicolumn{2}{|c|}{ Injury } \\
\hline & & Male & Female & & Acute & Chronic \\
\hline Auto & 36 & 27 & 9 & $31.1 \pm 5.7$ & 26 & 10 \\
\hline Allo & 35 & 27 & 8 & $33.4 \pm 6.4$ & 24 & 11 \\
\hline Value o & & \multicolumn{2}{|c|}{0.832} & 0.679 & \multicolumn{2}{|c|}{0.736} \\
\hline
\end{tabular}

were used for the comparison of continuous variables, and the $\chi^{2}$ test was used for categorical variables. The significance level was set at $p \leq 0.05$.

\section{Results}

Seventy-one patients (36 patients in the autograft group and 35 patients in the allograft group) met our inclusion criteria (Table I). The average follow-up of the autograft group was $3.2 \pm 0.2$ years and that of the allograft group was $3.3 \pm 0.6$ years, showing no difference $(p=0.764)$.

The average duration of the autograft procedure was longer than that of the allograft procedure. There was a difference between the two groups in fever time (when axillary temperature is more than $37.2^{\circ} \mathrm{C}$ ) and incision length. Patients in the autograft group had a longer incision and a shorter postoperative fever time (Table II).

The combined injuries included meniscus injury, cartilage lesion and media collateral ligament injury. Repair or partial meniscectomy was performed

Table II. General results of both groups

\begin{tabular}{|lccc|}
\hline Parameter & Auto & Allo & Value of $p$ \\
\hline $\begin{array}{l}\text { Operation time } \\
\text { [min] }\end{array}$ & $93.2 \pm 10.3$ & $83.6 \pm 8.1$ & 0.002 \\
\hline Fever time [day] & $4.3 \pm 1.1$ & $6.8 \pm 2.1$ & 0.005 \\
\hline Incision [cm] & $3.8 \pm 1.0$ & $1.6 \pm 0.8$ & 0.002 \\
\hline
\end{tabular}

for the meniscus injury. Debridement was performed for cartilage lesion. No treatment was performed for the media collateral ligament (Table III).

A significant difference was found in the posterior drawer test between the two groups at the final follow-up. The KT-2000 test results also showed a difference between the two groups in the tibia posterior displacement and in the average manual maximum KT-2000 side-to-side difference in posterior tibial displacement at $90^{\circ}$ knee flexion (Table IV).

Arthrofibrosis occurred in 3 patients in the autograft group and 4 patients in the allograft group. After physical therapy, the patient's knee ROM was improved greatly, without any impact on the final evaluation. No loss of flexion or extension was observed requiring manipulation and no debridement developed postoperatively in any patient in either group. There were 8 patients in the autograft group with leg muscle thrombosis and 7 patients in the allograft group, cured with conservative treatments. There was no significant difference between the two groups ( $p=0.614$ ). There was no infection in either group.

Numbness and dysesthesia around the incision were present in 22 patients in the autograft group (61\%), in contrast to 10 patients in the allograft group $(29 \%)(p=0.006)$. The area of numbness and dysesthesia was located at the anteromedial and anterolateral aspect of the knee mainly.

Table III. Intra-operative finding of two groups

\begin{tabular}{|lcccccccccccc|}
\hline \multirow{2}{*}{ Group } & \multicolumn{3}{c}{ Meniscus injury } & \multicolumn{4}{c}{ Cartilage lesion } & \multicolumn{4}{c|}{ Media ligament injury } \\
\cline { 2 - 15 } & Media & Lateral & Both & No & I & II & III & IV & 0 & I & II & III \\
\hline Auto & 16 & 15 & 5 & 18 & 13 & 5 & 0 & 0 & 31 & 5 & 0 & 0 \\
\hline Allo & 18 & 13 & 3 & 16 & 12 & 7 & 0 & 0 & 29 & 6 & 0 & 0 \\
\hline Value of $p$ & & 0.703 & & & & 0.788 & & & 0.705 \\
\hline
\end{tabular}

Table IV. Comparison of posterior stability and knee stability according to KT-2000 at the final follow-up

\begin{tabular}{|c|c|c|c|c|c|c|c|c|}
\hline \multirow[t]{2}{*}{ Group } & \multicolumn{4}{|c|}{ PDT } & \multirow{2}{*}{$\begin{array}{c}\text { Posterior tibia displacement } \\
\text { average }[\mathrm{mm}]\end{array}$} & \multicolumn{3}{|c|}{ Side to side difference } \\
\hline & 0 & 1 & II & III & & Value $[\mathrm{mm}]$ & $<3 \mathrm{~mm}$ & $>5 \mathrm{~mm}$ \\
\hline Auto & 23 & 8 & 5 & 0 & $3.8 \pm 1.5$ & $2.7 \pm 1.7$ & 23 & 4 \\
\hline Allo & 11 & 15 & 9 & 0 & $4.8 \pm 1.7$ & $3.6 \pm 2.0$ & 12 & 7 \\
\hline Value of $p$ & \multicolumn{4}{|c|}{0.024} & 0.031 & 0.038 & \multicolumn{2}{|c|}{0.045} \\
\hline
\end{tabular}


At the final follow-up, the average ROM was $132.3 \pm 2.2^{\circ}$ in the autograft and $134.6 \pm 1.8^{\circ}$ in the allograft group, showing no significant difference ( $p=0.875)$. The IKDC objective scale, Lysholm score and Tegner activity score showed greater improvement at the final follow-up compared to preoperation ( $p=0.006,0.001,0.005)$. There were no significant differences between the two groups at the final follow-up (Table V).

In both groups, the white blood cells (WBC), neutrophils, neutrophil\% and lymphomonocytes increased after surgery $(p=0.036,0.033,0.029$, 0.040 in the autograft group and $p=0.034$, $0.027,0.021,0.039$ in the allograft group). Also, the changes of the WBC and neutrophils in the allograft group were more significant than those in the autograft group ( $p=0.026,0.035)$. The lymphomonocyte\% remained stable after surgery compared to before in both groups. The mean number of leukomonocytes and percentage of leukomonocytes highly decreased after surgery $(p=0.031,0.039)$ (Table VI).

\section{Discussion}

Graft choice still remains controversial [24]. Which is best? In recent years there have been many reports about this topic, but the findings vary greatly [25-27]. Many studies have reported good clinical results using allografts for ligament reconstructions [28-31]. Compared to the auto- graft, the allograft has many advantages including minimizing postoperative donor-site morbidity, no weakening of the flexor apparatus, shorter operation time, and so on. The aim of our study was to compare the outcomes of arthroscopic posterior cruciate ligament reconstruction with different grafts. In our study, 71 patients underwent arthroscopic single bundle $\mathrm{PCL}$ reconstruction with an autograft or allograft. There was no difference between the two groups according to the IKDC, Lysholm score and Tegner activity score at the final follow-up. But the instrumented posterior laxity in the allograft group increased more than that in the autograft group. We also found that the incidence of numbness and dysesthesia around the incision in the autograft group was higher (61\% in autograft versus $28 \%$ in allograft group). Graft selection is a very important part of our preoperative planning. Our selection depended on the patients' preference, ages, expected outcomes, tissue availability and other factors.

Prodromos et al. reported that irradiated grafts had an abnormal stability rate of $31 \%$ vs. $12 \%$ for non-irradiated grafts [32]. In our study, the allogeneic tendons we used were sterilized with gamma irradiation at a dose of $2.5 \mathrm{mrad}$, by taking account that much gamma irradiation can greatly alter the initial biomechanical properties of allografts in a dose-dependent manner [33-35]. The gamma irradiation may change the biomechanical

Table V. Function evaluations and activity level at the final follow-up

\begin{tabular}{|c|c|c|c|c|c|c|c|}
\hline \multirow[t]{2}{*}{ Group } & \multirow[t]{2}{*}{$N$} & \multicolumn{2}{|c|}{ IKDC } & \multicolumn{2}{|c|}{ Lysholm } & \multicolumn{2}{|c|}{ Tegner } \\
\hline & & Pre & Follow-up & Pre & Follow-up & Pre & Follow-up \\
\hline Auto & 36 & $58.9 \pm 7.3$ & $81 \pm 9^{a}$ & $57.5 \pm 2.1$ & $82 \pm 9^{a}$ & $3.9 \pm 2.1$ & $7.7 \pm 1.2^{\mathrm{a}}$ \\
\hline Allo & 35 & $57.7 \pm 6.4$ & $80 \pm 10^{a}$ & $56.3 \pm 1.4$ & $84 \pm 8^{a}$ & $3.7 \pm 1.4$ & $7.1 \pm 1.6^{a}$ \\
\hline Value of $p$ & & 0.675 & 0.764 & 0.578 & 0.489 & 0.543 & 0.632 \\
\hline
\end{tabular}

asignificant differences comparing preoperation and postoperation $p<0.05$.

Table VI. Routine blood test results of both groups 1 day after operation

\begin{tabular}{|lcccccc|}
\hline Parameter & \multicolumn{4}{c}{ Auto } & & Allo \\
\cline { 2 - 7 } & Pre & Post & D (post-pre) & Pre & Post & D (post-pre) \\
\hline WBC & $6.82 \pm 1.73$ & $9.07 \pm 1.83^{*}$ & $2.26 \pm 1.65$ & $6.81 \pm 2.03$ & $10.33 \pm 2.36^{\star}$ & $3.52 \pm 2.26^{\star *}$ \\
\hline Neutrophils & $4.03 \pm 1.55$ & $7.12 \pm 1.65^{*}$ & $3.09 \pm 1.47$ & $3.83 \pm 1.34$ & $8.11 \pm 2.03^{*}$ & $4.29 \pm 1.81^{\star *}$ \\
\hline Neutrophil\% & $57.85 \pm 8.84$ & $76.36 \pm 6.08^{*}$ & $18.51 \pm 6.44$ & $55.71 \pm 6.50$ & $78.23 \pm 5.37^{\star}$ & $22.52 \pm 8.22$ \\
\hline Lymphomonocytes & $0.51 \pm 0.17$ & $0.72 \pm 0.25^{*}$ & $0.22 \pm 0.25$ & $0.54 \pm 0.19$ & $0.76 \pm 0.27^{\star}$ & $0.22 \pm 0.22$ \\
\hline Lymphomonocyte\% & $7.41 \pm 1.65$ & $7.88 \pm 2.43$ & - & $7.96 \pm 1.55$ & $7.31 \pm 1.80$ & - \\
\hline Leukomonocytes & $2.06 \pm 0.49$ & $1.30 \pm 0.37^{*}$ & $-0.75 \pm 0.34$ & $2.22 \pm 0.64$ & $1.35 \pm 0.44^{*}$ & $-0.87 \pm 0.44$ \\
\hline Leukomonocyte\% & $31.54 \pm 8.80$ & $14.22 \pm 4.47^{*}$ & $-17.31 \pm 0.68$ & $33.07 \pm 6.18$ & $13.27 \pm 4.46^{*}$ & $-19.80 \pm 7.17$ \\
\hline
\end{tabular}

*Significant differences comparing preoperation and postoperation within the group $p<0.05 .{ }^{* *}$ Significant differences comparing autograft and allograft groups in D (post-pre) $p<0.05$. 
properties. The change of the biomechanical properties may lead to posterior laxity. Other papers have reported that the enlarged tunnel was partly responsible for the laxity $[36,37]$.

The sensory disturbance postoperatively was mainly located at the anteromedial and anterolateral aspect of the knee, where the infrapatellar branch of the saphenous nerve was supplied. Since the nerve is found immediately superficial to the gracilis tendon [38], the hamstring harvesting could damage the branches of the saphenous nerve [39].

We performed a routine blood test for every patient 1 day postoperatively. We found that the numbers of neutrophilic granulocytes and white blood cells in the allograft group essentially increased postoperatively in comparison to those in the autograft group. It is possible that a relationship exists between the elevation of WBC and postoperative fever time, but this needs further evidence-based tests.

There were some limitations in our study. First, the follow-up was not very long, so some long-term outcomes could not be observed. Second, the group of patients was relatively small, and a post hoc power analysis was not performed; its statistical power would be affected. Third, the graft selection was performed based on patients' preference. Fourth, the routine blood test was only performed 1 day postoperatively, without indicating the trend of changes of blood cells. The relationship between the changes of blood routine parameters and the postoperative symptoms still needs further investigation.

In conclusion, both groups of patients had satisfactory clinical outcomes after the operation. There were no differences in functional test results between the 2 groups. However, in the instrumented posterior laxity test, the autograft gave better results than the allograft.

\section{Conflict of interest}

The authors declare no conflict of interest.

\section{References}

1. Shelbourne KD, Davis TJ, Patel DV. The natural history of acute, isolated, nonoperatively treated posterior cruciate ligament injuries. A prospective study. Am J Sports Med 1999; 27: 276-83.

2. Fanelli GC, Edson CJ. Posterior cruciate ligament injuries intrauma patients: part II. Arthroscopy 1995; 11: 526-9.

3. Fanelli GC, Edson CJ. Arthroscopically assisted combined anterior and posterior cruciate ligament reconstruction in the multiple ligament injured knee: 2- to 10-year follow-up. Arthroscopy 2002; 18: 703-14.

4. Ibrahim SA, Ahmad FH, Salah M, et al. Surgical management of traumatic knee dislocation. Arthroscopy 2008; 24: 178-87.

5. Liow RYL, McNicholas MJ, Keating JF, et al. Ligament repair and reconstruction in traumatic dislocation of the knee. J Bone Joint Surg-Series B 2003; 85: 845-51.
6. Tzurbakis M, Diamantopoulos A, Xenakis T, et al. Surgical treatment of multiple knee ligament injuries in 44 patients: 2-8 years follow-up results. Knee Surg Sports Traumatol Arthrosc 2006; 14: 739-49.

7. Patel DV, Allen AA, Warren RF, et al. The nonoperative treatment of acute, isolated (partial or complete) posterior cruciate ligament-deficient knees: an intermediate-term follow up study. HSS J 2007; 3: 137-46.

8. Keller PM, Shelbourne KD, McCarroll JR, et al. Nonoperatively treated isolated posterior cruciate ligament injuries. Am J Sports Med 1993; 21: 132-6.

9. Fanelli GC, Beck JD, Edson CJ. Current concepts review: the posterior cruciate ligament. J Knee Surg 2010; 23: 61-72.

10. Mascarenhas R, MacDonald PB. Anterior cruciate ligament reconstruction: a look at prosthetics: past, present and possible future. McGill J Med 2008; 11: 29-37.

11. West RV, Harner CD. Graft selection in anterior cruciate ligament reconstruction. J Am Acad Orthop Surg 2005; 13: 197-207.

12. Nyland J, Caborn DN, Rothbauer J, et al. Two-year outcomes following $A C L$ reconstruction with allograft tibialis anterior tendons: a retrospective study. Knee Surg Sports Traumatol Arthrosc 2003; 11: 212-8.

13. Fu FH, Bennett $\mathrm{CH}, \mathrm{Ma} \mathrm{CB}$, et al. Current trends in anterior cruciate ligament reconstruction. Part II: Operative procedures and clinical correlations. Am J Sports Med 2000; 28: 124-30.

14. Kim JG, Yang SJ, Lee YS, Shim JC, Ra HJ, Choi JY. The effects of hamstring harvesting on outcomes in anterior cruciate ligament-reconstructed patients: a comparative study between hamstring-harvested and -unharvested patients. Arthroscopy 2011; 27: 1226-34.

15. Sun K, Zhang J, Wang Y, et al. Arthroscopic anterior cruciate ligament reconstruction with at least 2.5 years' follow-up comparing hamstring tendon autograft and irradiated allograft. Arthroscopy 2011; 27: 1195-202.

16. Bach BR Jr. ACL reconstruction: revisited, revised, reviewed. J Knee Surg 2004; 17: 125-6.

17. Krych AJ, Jackson JD, Hoskin TL, Dahm DL. A meta-analysis of patellar tendon autograft versus patellar tendon allograft in anterior cruciate ligament reconstruction. Arthroscopy 2008; 24: 292-8.

18. Kustos T, Balint L, Than P, Bárdos T. Comparative study of autograft or allograft in primary anterior cruciate ligament reconstruction. Int Orthop 2004; 28: 290-3.

19. Li CM, Ho YR, Liu YC. Transmision of human immunodeficiency virus through bone transplantation: a case report. J Formos Med Assoc 2001; 100: 350-1.

20. Jackson DW, Grood ES, Goldstein JD, et al. A comparison of patellar tendon autograft and allograft used for anterior cruciate ligament reconstruction in the goat model. Am J Sports Med 1993; 21: 176-85.

21. Rodrigo JJ, Jackson DW, Simon TM, Muto KN. The immune response to freeze dried bone tendon bone allografts in humans. Am J Knee Surg 1993; 6: 347-53.

22. Fahey $M$, Indelicato PA. Bone tunnel enlargement after anterior cruciate ligament replacement. Am J Sports Med 1994; 22: 410-4.

23. Dutka J, Skowronek M, Skowronek P, Dutka L. Arthroscopic verification of objectivity of the orthopaedic examination and magnetic resonance imaging in intra-articular knee injury. Retrospective study. Videosurgery Minininv 2012; 7: 13-8.

24. Sherman $\mathrm{OH}$, Banffy MB. Anterior cruciate ligament reconstruction: which graft is best? Arthroscopy 2004; 20: 974-80. 
25. Chang SKY, Egami DK, Shaib MD, Kan DM, Richardson AB. Anterior cruciate ligament reconstruction: allograft versus autograft. Arthroscopy 2003; 19: 453-62.

26. Siebold R, Buelow JU, Bös L, Ellermann A. Primary ACL reconstruction with fresh-frozen patellar versus Achilles tendon allografts. Arch Orthop Trauma Surg 2003; 123: 180-5.

27. Kustos T, Balint L, Than P, Bardos T. Comparative study of autograft or allograft in primary anterior cruciate ligament reconstruction. Int Orthop 2004; 28: 290-3.

28. Zhao J, Huangfu X. Arthroscopic single-bundle posterior cruciate ligament reconstruction: retrospective review of 4- versus 7-strand hamstring tendon graft. Knee 2007; 14: 301-5.

29. Wang CJ, Chan YS, Weng LH, et al. Comparison of autogenous and allogenous posterior cruciate ligament reconstructions of the knee. Injury 2004; 35: 1279-85.

30. Carey JL, Dunn WR, Dahm DL, Zeger SL, Spindler KP. A systematic review of anterior cruciate ligament reconstruction with autograft compared with allograft. J Bone Joint Surg Am 2009; 91: 2242-50.

31. Bach BR Jr, Aadalen KJ, Dennis MG, et al. Primary anterior cruciate ligament reconstruction using fresh-frozen, nonirradiated patellar tendon allograft: minimum 2-year follow-up. Am J Sports Med 2005; 33: 284-92.

32. Prodromos C, Joyce B, Shi K. A meta-analysis of stability of autografts compared to allografts after anterior cruciate ligament reconstruction. Knee Surg Sports Traumatol Arthrosc 2007; 15: 851-6.

33. Curran AR, Adams DJ, Gill JL, Steiner ME, Scheller AD. The biomechanical effects of low-dose irradiation on bone-patellar tendon-bone allografts. Am J Sports Med 2004; 32: 1131-5.

34. Grieb TA, Forng RY, Bogdansky S, et al. High-dose gamma irradiation for soft tissue allografts: high margin of safety with biomechanical integrity. J Orthop Res 2006; 24: 1011-8.

35. Balsly CR, Cotter AT, Williams LA, et al. Effect of low dose and moderate dose gamma irradiation on the mechanical properties of bone and soft tissue allografts. Cell Tissue Bank 2008; 9: 289-98.

36. Jagodzinski M, Foerstemann T, Mall G, Krettek C, Bosch U, Paessler $\mathrm{HH}$. Analysis of forces of $\mathrm{ACL}$ reconstructions at the tunnel entrance: is tunnel enlargement a biomechanical problem? J Biomech 2005; 38: 23-31.

37. Zysk SP, Fraunberger P, Veihelmann A, et al. Tunnel enlargement and changes in synovial fluid cytokine profile following anterior cruciate ligament reconstruction with patellar tendon and hamstring tendon autografts. Knee Surg Sports Arthrosc 2004; 12: 98-103.

38. Cross MJ, Roger G, Kujawa P, Anderson IF. Regeneration of the semitendinosus and gracilis tendons following their transection for repair of the anterior cruciate ligament. Am J Sports Med 1992; 20: 221-3.

39. Vardi G. Sciatic nerve injury following hamstring harvest. Knee 2004; 11: 37-9. 